\title{
Inflammatory Myofibroblastic Tumor of Proximal Urethra in a Pregnant Female: A Unique Case Report
}

\author{
Kumar $\mathrm{GA}^{* 1}$, Venkateswarlu $\mathrm{MC}^{2}$, Reddy $\mathrm{MN}^{3}$, Babu $\mathrm{BP}^{4}$, Koti $\mathrm{K}^{5}$ and Kumar $\mathrm{A}^{6}$ \\ ${ }^{1}$ Department of Urology, Sentini Hospitals, Vijayawada, Andhra Pradesh, India \\ ${ }^{2}$ Department of General Surgery, Siddhartha Medical College, Vijayawada, Andhra Pradesh, India \\ ${ }^{3}$ Department of Urology, Kamineni Hospitals, Hyderabad, Telangana, India \\ ${ }^{4}$ Department of Radiology, Sentini Hospitals, Vijayawada, Andhra Pradesh, India \\ ${ }^{5}$ Department of Pathology, Sentini Hospitals, Vijayawada, Andhra Pradesh, India \\ ${ }^{6}$ Department of Anaesthiology, Sentini Hospitals, Vijayawada, Andhra Pradesh, India
}

*Corresponding author: Kumar GA, Department of Urology, Sentini Hospitals, Vijayawada, Andhra Pradesh, India, Tel: +91 9666940001, E-mail: drajay707@gmail.com

Citation: Kumar GA, Venkateswarlu MC, Reddy MN, Babu BP, Koti K, et al. (2016) Inflammatory Myofibroblastic Tumor of Proximal Urethra in a Pregnant Female: A Unique Case Report. J Case Rep Stud 4(1): 108. doi: 10.15744/2348-9820.4.108

Received Date: October 16, 2015 Accepted Date: February 12, 2016 Published Date: February 16, 2016

\begin{abstract}
Inflammatory Myofibroblastic tumour (IMT) is a rare spindle tumour that mimics malignant processes. It can affect any part of the body, but rarely occurs in the genitourinary tract. We report a case of urethral IMT in a 31-year-old pregnant female of 18 weeks gestational age. The diagnosis was established by histopathological findings. This is the first documented case in the world, as no such documentation has been made in a pregnant female.
\end{abstract}

Keywords: Myofibroblasts; Tumor; Urethra

\section{Introduction}

Inflammatory Myofibroblastic tumour (IMT) is a rare entity of vague etiology and pathogenesis [1]. It appears to be a benign process mimicking malignant processes. IMT can affect any part of the body, but is common in the lung and orbit [2]. It rarely occurs in the genitourinary tract, in which the bladder is its most common site [3]. We report a case of urethral IMT in a 31-yearold pregnant female of 18 weeks gestational age.

\section{Case History}

A 31-year-old pregnant woman of 18 weeks gestational age presented to our hospital. She complained of increased frequency of urination and obstructive urinary symptoms of 10 days duration. She has 1 male child. She had no previous disease/illnesses and she did not smoke. Physical examination of the external genitalia was done in the lithotomy position, which did not reveal a mass at the external urethral meatus. Ultrasonography of the KUB region was performed which revealed a polypoidal mass of size $3.8^{\star} 2.5 \mathrm{~cm}$ originating near the bladder neck (Figure 1a,b). Confirmation was done by MRI of the pelvis (Figure 2 ). The mass was planned to be excised after explaining associated risks regarding outcomes of pregnancy. Thereafter, cystoscopy was performed which showed a mass originating from the proximal urethra and projecting into bladder (Figure $3 \mathrm{a}, \mathrm{b}$ and $\mathrm{c}$ ). Near total resection of the tumour was done and the mass was examined histopathologically. Histopathological findings showed fascicules of spindle cell proliferation consisting of fibroblastic and myofibroblastic cells accompanied by a prominent infiltration of lymphocytes and plasma cells. Immunochemically the tumor cells were positive for Alk-1 antigen (Figure 4a,b and c). Post-operatively there were neither maternal nor fetal complications. The patient's symptoms improved and the fetus is doing well at 7 weeks follow-up. 


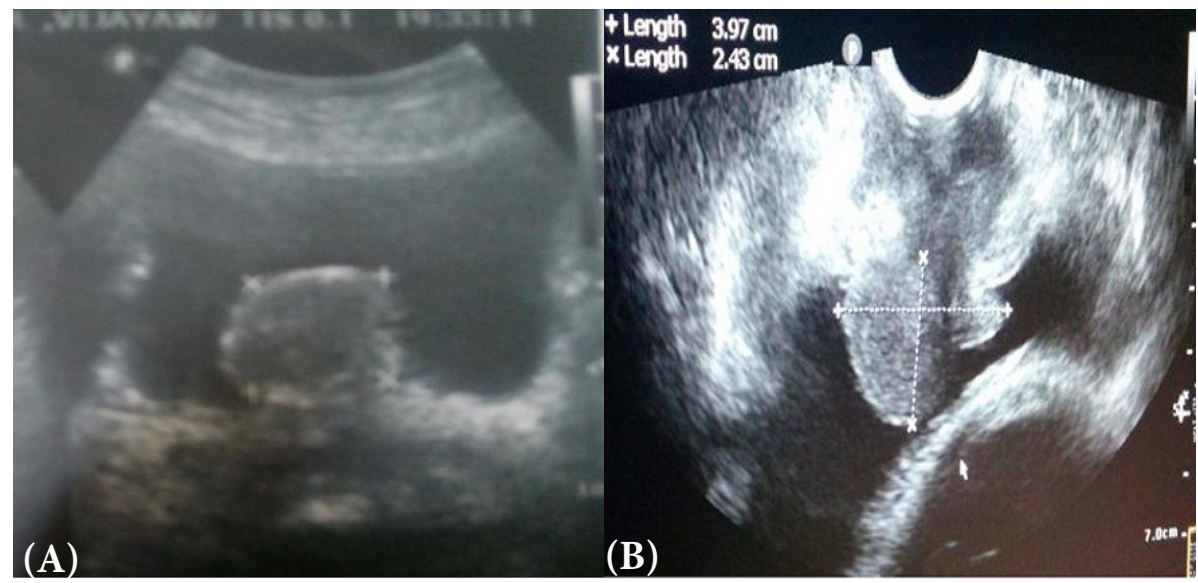

Figure 1: A) Trans-Abdominal USG showing a polypoid mass of size $3.8^{\star} 2.5 \mathrm{cms}$ in the bladder; $\mathbf{B}$ ) Trans-Vaginal USG showing similar findings

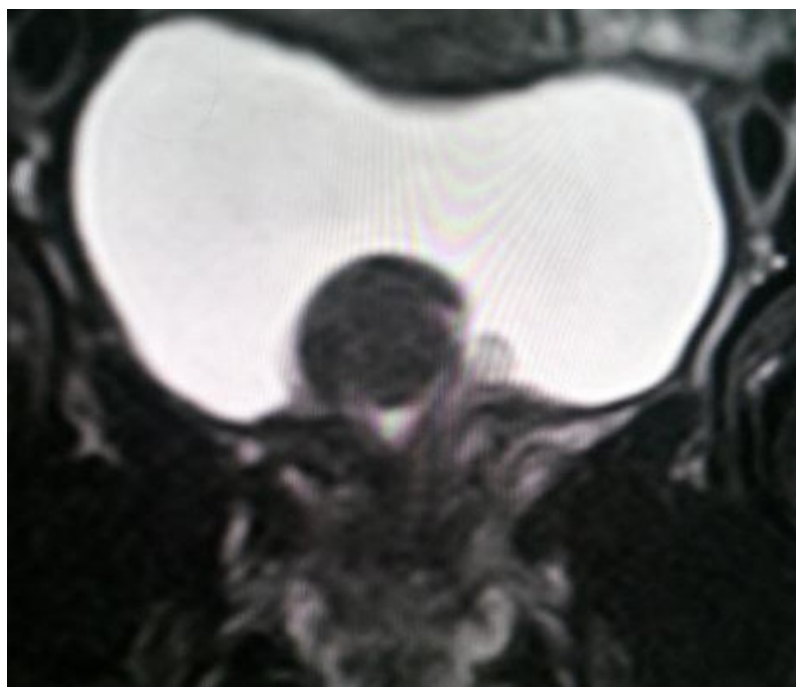

Figure 2: MR Pelvis showing $3.8^{\star} 2.5 \mathrm{~cm}$ s tumor originating from the neck of bladder
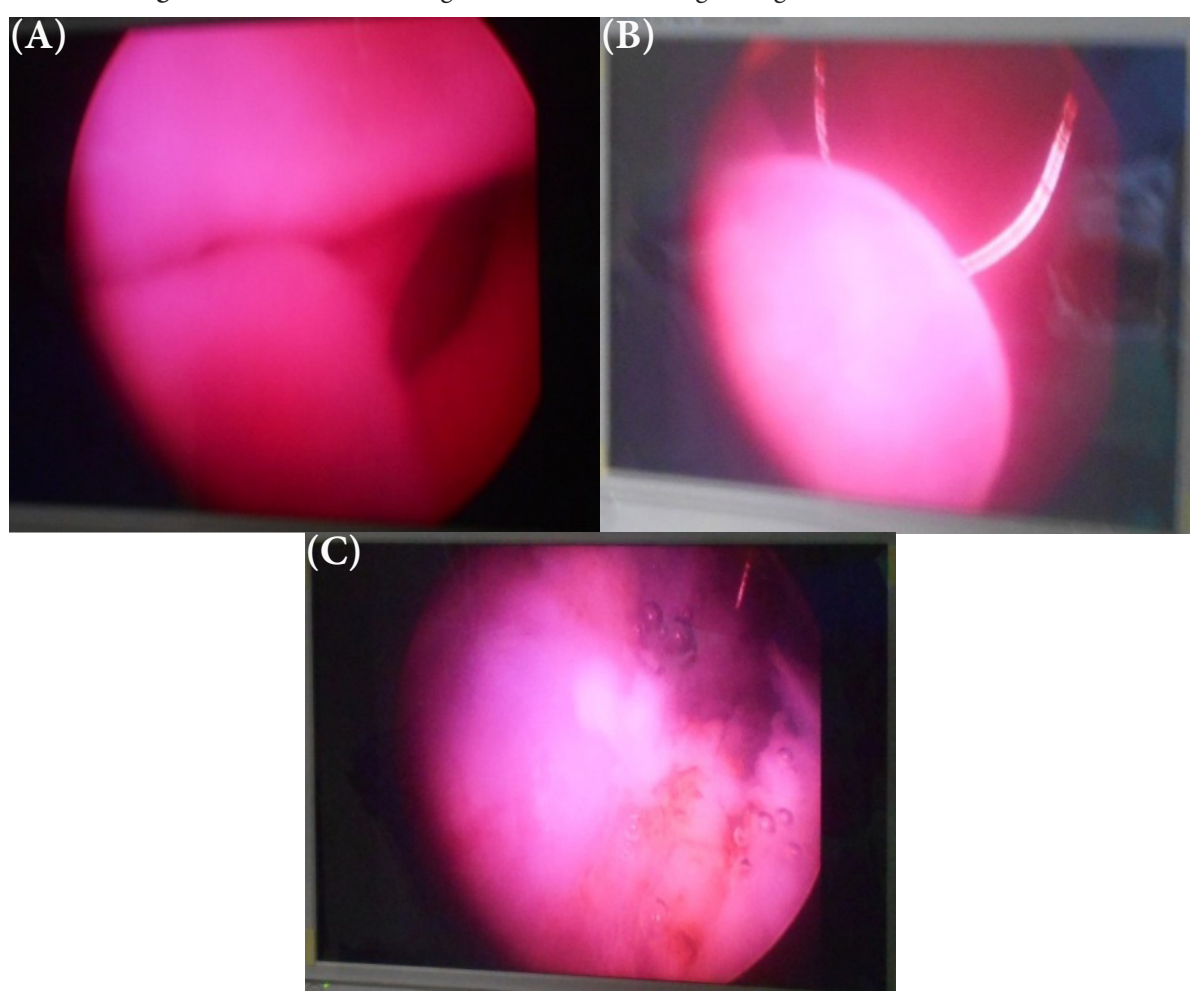

Figure 3: A) Intra-operative cystoscopy images showing tumor arising from the proximal urethra and extending into bladder; B) Resection of the tumor; C) Post resection image in the proximal urethra 

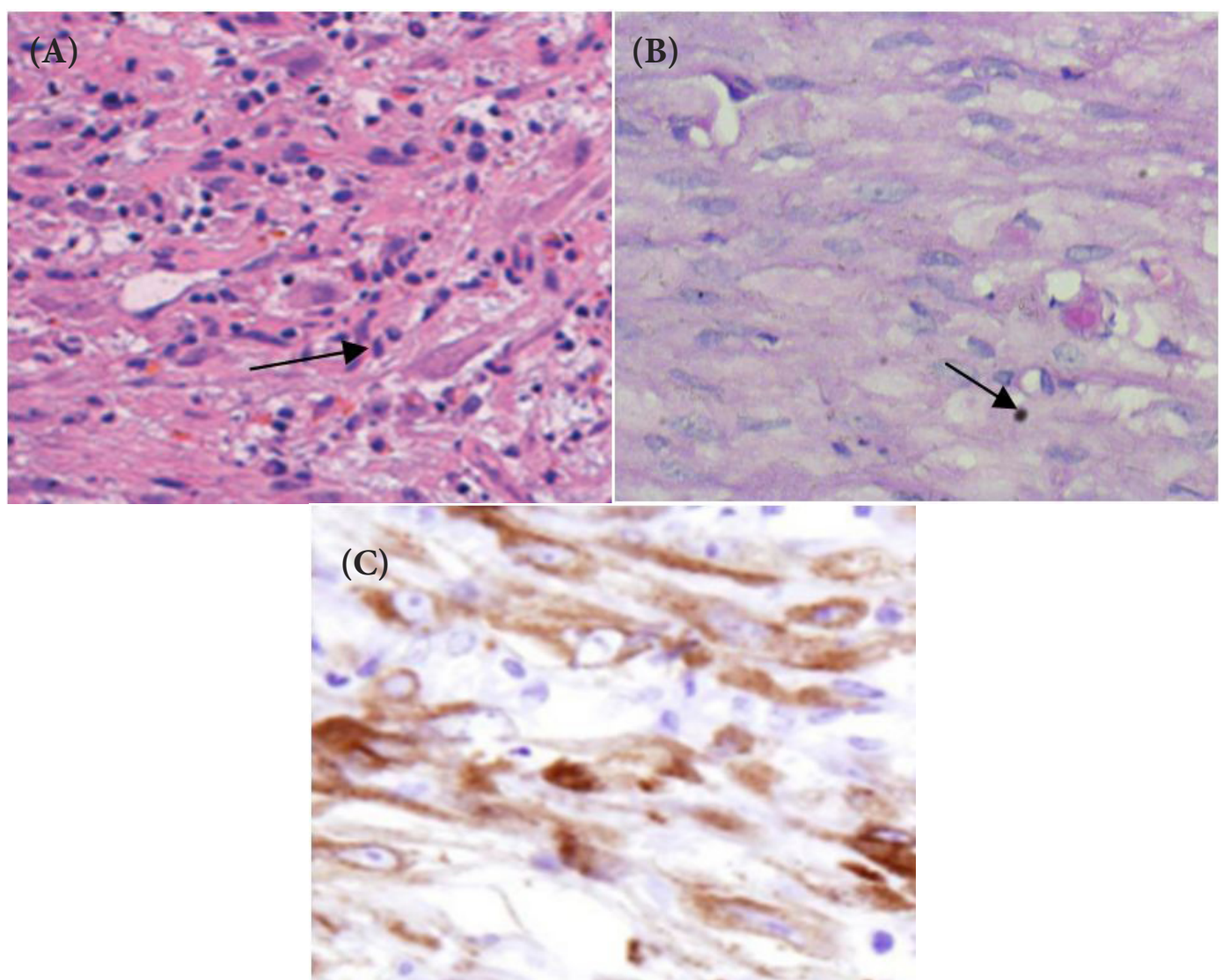

Figure 4: A) Inflammatory cells like plasma cells indicated by arrow, lymphocytes and granulocytes (H\&E staining $\times 20$ ); B) Photomicrograph showing spindle cells with vesicular chromatin and a small inconspicuous nucleolus indicated by arrow (H\&E x400); C) Immunochemically the tumor cells were positive for Alk-1 antigen

\section{Discussion}

Inflammatory Myofibroblastic Tumour is a rare spindle tumour which mimics malignant lesions [4]. Because of its histological heterogeneity, it has received many names over the past years, including plasma cell pseudotumor, inflammatory pseudotumor, xanthomatous pseudotumor, pseudosarcomatous myofibroblastic proliferation, inflammatory myofibrohistiocytic proliferation, atypical fibromyxoid tumor and atypical myofibroblastic tumour [3-5]. It is not clear whether IMT is benign, malignant or part of a spectrum of benign to malignant spindled soft tissue tumours. The World Health Organization continues to classify myofibroblastic tumour as a distinct borderline lesion with uncertainty as to whether it is reactive or neoplastic in nature.

Since IMT was first reported by Symmers in 1921, IMT has been found at various organs [6]. Although the lung is the best known and most common site, it has subsequently been recognized involving a wide variety of anatomic sites. In the genitourinary tract IMT has been reported in the kidney, urethra, prostate, ureter and rete testis but is most frequently observed in the bladder [4]. While pulmonary IMT occurs more commonly in mid-adulthood, extrapulmonay IMT occurs more often in the soft tissues and viscera of children and young adults [7].

Radiologic findings of inflammatory pseudotumor in the genitourinary tract (e.g., kidney and bladder) are nonspecific. Ultrasound imaging and contrast-enhanced computed tomography findings show variable patterns, whereas magnetic resonance imaging shows a hypointense lesion on T1-and T2-weighted images (possibly reflecting the fibrotic change) and shows marked gadolinium enhancement. These variable radiologic findings may be attributed to the various degrees of fibrosis, cellular infiltration, and dynamic change occurring during the inflammatory process. So although definite radiologic differentiation from malignancy is not clearly possible, manifestations of inflammatory pseudotumor and also imaging-guided biopsy can help avoid unnecessary radical surgery [8]. However, due to the specific location of urethral IMT, it seems that radiology cannot be very helpful in its diagnosis.

Patients may present with fever, weight loss, growth retardation, thrombocytosis, iron deficiency anemia, hypergammaglobulinemia, symptoms related to mass effect, or a combination of these signs and symptoms [2]. 
The differential diagnosis of IMT includes both benign and malignant lesions. Leiomyoma is a benign smooth muscle neoplasm that very rarely becomes cancer $(0.1 \%)$. They can occur in any organ, but the most common forms occur in the uterus, small bowel, and the esophagus, which stains positively for vimentin, smooth muscle actin and desmin, similar to IMT. Nodular fasciitis, also known as nodular pseudosarcomatous fascitis, pseudosarcomatous fascitis, and subcutaneous pseudosarcomatous fibromatosis, is a benign [9] soft tissue lesion most commonly found in the superficial fascia. The lesion commonly occurs in the first three decades of life. Upper extremities and trunk are the most common affected anatomical sites. Previous history of trauma may be present. Clinically and histologically, nodular fasciitis may be mistaken for a sarcoma. Also leiomyosarcoma, sarcomatoid carcinoma and rhabdomyosarcoma are malignant lesions which can be categorized in the differential diagnosis of IMT. Leiomyosarcoma is a relatively rare form of cancer, and accounts for 5-10\% of soft tissue sarcomas, which are in them relatively rare [10]. Leiomyosarcomas can be very unpredictable. They can remain dormant for long periods of time and recur after years. It is a resistant cancer, meaning generally not very responsive to chemotherapy or radiation. A rhabdomyosarcoma, commonly referred to as RMS, is a type of cancer, specifically a sarcoma (cancer of connective tissues), in which the cancer cells are thought to arise from skeletal muscle progenitors. It can also be found attached to muscle tissue, wrapped around intestines, or in any anatomic location. It mostly occurs in areas naturally lacking in skeletal muscle, such as the head, neck, and genitourinary tract.

The microscopic features of the IMT are a myxoid, spindle cell dominant and less compact appearance [11]. In all of the lesions, the mixed inflammatory infiltration was a distinctive microscopic feature. The spindle cells were reactive with antibodies to vimentin, smooth muscle actin, and muscle-specific actin in a majority of cases [7]. Three basic histological patterns are recognized, which are myxoid/vascular, compact spindle cells, and hypocellular fibrous patterns [11]. The three patterns might be equally represented with one blending into another, or one or two patterns might predominate. And none of which had any discernible relationship to prognosis.

Typical IMTs can be locally aggressive, sometimes requiring radical surgical resection. Metastasis is not seen in typical cases with only a rare incidence of malignant transformation and remote metastasis [5].

While reviewing the literature, only 3 cases of IMT of the urethra in a female patient have been documented [12-14]. No documentation of IMT in a pregnant female urethra has been made yet.

\section{Conclusion}

Although rare, IMT should be considered in the differential diagnosis of urethral masses in female patients. Also, both the surgeon and patient should be aware of its probable risk of malignant transformation and recurrence; therefore follow-up is warranted.

\section{References}

1. Li Z, Wang W, Wang Y, Zhai X, Tian Y, et al. (2013) Inflammatory myofibroblastic tumor of the kidney with viral hepatitis B and trauma: A case report. Oncol Lett 6: 1741-3.

2. Patnana M, Sevrukov AB, Elsayes KM, Viswanathan C, Lubner M, et al. (2012) Inflammatory pseudotumor: the great mimicker. AJR Am J Roentgenol 198: W217-27.

3. Zhang HH, Qi F, Zu XB, Xu L, Liu LF, et al. (2012) Recurrence of inflammatory myofibroblastic tumor in bladder secondary to prostate treated with laparoscopic radical cystectomy. Med Sci Monit 18: CS63-66.

4. Cheng L, Foster SR, MacLennan GT, Lopez-Beltran A, Zhang S, et al. (2008) Inflammatory myofibroblastic tumors of the genitourinary tract--single entity or continuum? J Urol 180: 1235-40.

5. Montgomery EA, Shuster DD, Burkart AL, Esteban JM, Sgrignoli A, et al. (2006) Inflammatory myofibroblastic tumors of the urinary tract: a clinicopathologic study of 46 cases, including a malignant example inflammatory fibrosarcoma and a subset associated with high-grade urothelial carcinoma. Am J Surg Pathol 30: $1502-12$.

6. Lim SJ, Kim GY, Park JH, Kim YW, Park YK, et al. (1999) Inflammatory Myofibroblastic Tumor of the Mesentery: A case report. Korean J Pathol 33: 729-32.

7. Coffin CM, Watterson J, Priest JR, Dehner LP (1995) Extrapulmonary inflammatory myofibroblastic tumor (inflammatory pseudotumor). A clinicopathologic and immunohistochemical study of 84 cases. Am J Surg Pathol 19: 859-72.

8. Park SB, Cho KS, Kim JK, Lee JH, Jeong AK, et al. (2008) Inflammatory pseudotumor (myoblastic tumor) of the genitourinary tract. AJR Am J Roentgenol 191: 1255-62.

9. Sailon AM, Cappuccino G, Hameed M, Fleegler EJ (2008) Nodular Fasciitis of the Hand Over the Metacarpophalangeal Joint: A Case Report. Eplasty 8: e38.

10. Weaver MJ, Abraham JA (2007) Leiomyosarcoma of the Bone and Soft Tissue: A Review. ESUN 4.

11. Coffin CM, Humphrey PA, Dehner LP (1998) Extrapulmonary inflammatory myofibroblastic tumor: a clinical and pathological survey. Semin Diagn Pathol 15: $85-101$.

12. Song PH, Lim HS, Kim MJ, Jung HC (2009) A Case of Inflammatory Myofibroblastic Tumor of the Urethra with Overactive Bladder. Int Neurourol J 13: 80-82.

13. Aslzare M, Jafarian A, Ghoreifi A (2014) Inflammatory myofibroblastic tumour in a female urethra: A rare benign lesion that mimics malignancy. Can Urol Assoc J 8: E891-3.

14. Regmi SK, Walia R, Kumar R (2014) An unusual cause of urinary retention in a young female: a case report. Urol Int 93: 122-4. 


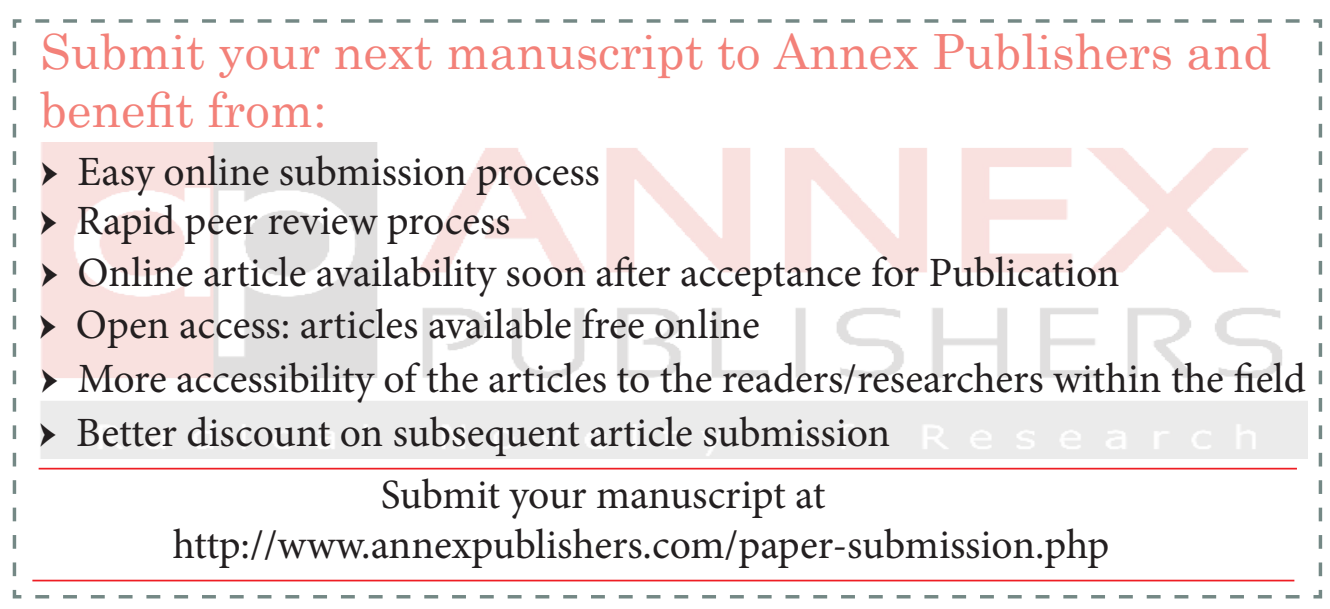

